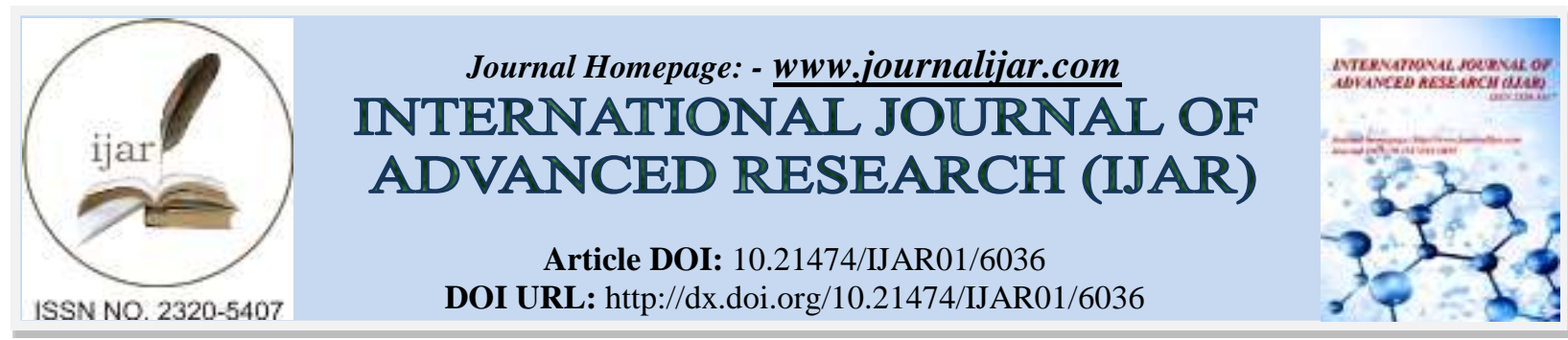

RESEARCH ARTICLE

\title{
FINITE ELEMENT ANALYSIS OF BEHAVIOR OF POST TENSIONED CONCRETE BEAMS WITH OPENINGS IN SHEAR REGIONS.
}

\author{
Hamdy shehabeldin ${ }^{1}$, htem gheith ${ }^{2}$, salah abdel-megeed ${ }^{3}$ and emadeldin zaki ${ }^{4}$. \\ 1. Professor, Faculty of Engineering, Zagazig University. \\ 2. Professor, Housing and Development Research Center. \\ 3. Associate Professor, Faculty of Engineering, Zagazig University. \\ 4. Research Engineer, Ph. D candidate.
}

\section{Manuscript Info}

Manuscript History

Received: 12 October 2017

Final Accepted: 14 November 2017

Published: December 2017

\begin{abstract}
In tall buildings, there is a trend towards providing opening through the webs of reinforced concrete beams to accommodate service ducts. But reinforced concreate beams have sectional loss by web opening. So sometimes severe cracks having large width may appear near web opening, and those severe cracks may affect the performance of the reinforced concrete beam. To improve the situation it is proposed to introduce prestess force to the beam before loading. The prestess force is loaded by prestress tendons arranged near the tension layer of the beam. Finite element analyses are now widely used \& become the choice of modern engineering tools for the researcher. In the present study the prestressed beam with opening across the web is numerically simulated to evaluate its performance. The problem is modeled as nonlinear elasto-plastic beam and numerically simulated utilizing finite element method. A numerical investigation was carried out on ANSYS 14.0 for a beam with different opening dimensions and different opening locations on its span. Computer based modeling results are compared to the experimental, the comparison shows that computer modeling can be an excellent alternative of the destructive laboratory tests with good acceptance.
\end{abstract}

Copy Right, IJAR, 2017,. All rights reserved.

\section{Introduction:-}

The provision of transverse openings in floor beams to facilitate the passage of utility pipes and service ducts results not only in a more systematic layout of pipes and ducts, it also translates into substantial economic savings in the construction of a multi-story building. Extensive research has been carried out giving a comprehensive coverage on both circular and large rectangular openings under various combinations of bending, shear and torsion. In the construction of modern buildings, a network of pipes and ducts is very necessary to accommodate essential services like water supply, sewage, air-conditioning, electricity, telephone, and computer network. Usually, these pipes and ducts are placed underneath the beam soffit and for aesthetic reasons are covered by a suspended ceiling, thus creating a dead space. Passing these ducts through transverse openings in the floor beams leads to a reduction in the dead space results in a more compact design. For small buildings, the savings thus achieved may not be significant, but for multistory buildings, any saving in story height multiplied by the number of stories can represent a 
substantial saving in total height, length of air-conditioning and electrical ducts, plumbing risers, wall and partition surfaces, and overall load on the foundation. Beam openings may be of different shapes, size and are generally close to the supports where shear is dominate. In practical life it quite often use to provide convenient passage of environmental services which reduce the story heights of buildings and weight of concrete beams as it improves the demand on the supporting frame both under gravity loading and seismic excitation which results in major cost saving. Openings should be positioned on concrete beams to provide chords with sufficient concrete area for developing ultimate compression block in flexure and adequate depth for providing effective shear reinforcement. Hanson (1969) tested a typical joist floor i.e. a series of longitudinally RC T-beams representing square and circular openings in the web and found that an opening located adjacent to the center stub (support) produced no reduction in strength [1].

The test data reported by Somes and Corley (1974) indicated that when a small openings (0.25) times the depth of the beam is introduced in the web of a beam which is unreinforced in shear, the mode of failure remains essentially the same as that of a solid beam [2].

Salam (1977) investigated perforated beams of rectangular cross section under two symmetrical point loads [3]. Siao and Yap (1990) stated that that the beams fail prematurely by sudden Formation of diagonal crack in the compression chord when no additional reinforcement is provided in the members near the opening (chord members) [4].

Mansur et al (1991) tested eight (8) RC continuous beams, each containing a large transverse openings and found an increase in depth of opening led to a reduction in collapse load [5]. Mansur (1998) [6], discussed about the effects of transverse opening on the behavior and strength of RC beams under predominant shear and stated that opening represents a source of weakness and the failure plane always passes through the opening, except when the opening is very close to the support so as to bypass the potential inclined failure plane. Abdalla et al. (2003) used fiber reinforced polymer (FRP) sheets to strengthen the opening region [7].

T H Kim et al (2012) verified the numerical method for the evaluation of behavior and strength of prestressed concrete deep beams by comparing numerical results with reliable experimental results by using a sophisticated nonlinear finite element analysis program. They applied tensile, compressive and shear models of cracked concrete and models of reinforcing and prestressing steel were used to account for the material nonlinearity of prestressed concrete. The smeared crack approach was incorporated. A bonded or un-bonded prestressing bar elements are used based on the finite element method, which can represent the interaction between the prestressing bars and concrete of a prestressed concrete member. [8]

Abdul Ridah and Hayder 2015, present an experimental investigation of reinforced concrete slabs with openings and strengthened with (CFRP) sheets, all slabs tested under uniformly distributed load with simply supports on the four edges by using high strength concrete. The experimental work includes testing of sixteen reinforced concrete slab specimens with dimensions (1050x1050) $\mathrm{mm}$ and (80) $\mathrm{mm}$ depth, as well as a series of tests carried out on construction materials. Experimental results showed that the presence of the openings, the unstrengthen specimens showed a decrease in ultimate load capacity between $(20.3 \%-29.6 \%)$ with respect to the control solid slab especially slabs with two converging opening showed a significant decrease in ultimate load capacity. On the other hand, the test results clearly demonstrated that the use of CFRP depends on the strengthening scheme which leads to a significant improvements by $(33.3 \%-87.5 \%)$ in the cracking load and $(26.2 \%-55.1 \%)$ in the ultimate load compared with unstrengthen slab with opening. The experimental tests also showed the slab specimen with two diagonal diverging opening and strengthening with CFRP by second scheme leading to the best results in cracking load by $(36.4 \%)$ and ultimate load (21.8\%) as compared with the control solid slab. [9]

M.A. Mansur, [2006], investigates the problem of openings in beams, the author initiated a research program in the early 1980s. The major findings relevant to the analysis and design of such beams under the most commonly encountered loading case of bending and shear are extracted and summarized. His attempt has been made to answer the frequently asked questions related to creating an opening in an already constructed beam and how to deal with multiple openings. It has been shown that the design method for beams with large openings can be further simplified without sacrificing rationality and having unreasonable additional cost. [10] 


\section{Prestressing Basic and Concept:-}

Prestress concrete is basically concrete in which internal stresses of a suitable magnitude and distribution are introduced so that stresses resulting from external loads are counteracted to a desired degree. In reinforced concrete members, the prestress is commonly introduced by tensioning the steel reinforcement.

\section{Advantages Of Prestressed Concrete:-}

Prestressed concrete offers great technical advantages in comparison with other forms of construction, such as reinforced concrete and steel. In the case of fully prestressed members, which are free from tensile stresses under working loads, the cross section is more effectively utilized when compared with a reinforced concrete section which is cracked under working loads. Within certain limits, a permanent dead-load may be counteracted by increasing the eccentricity of the prestessing force in a prestressed structural element, thus effecting savings in the use of materials. Prestressed concrete members possess improved resistance to shearing forces, due to the effect of compressive prestress, which reduces the principal tensile stress. The use of curved cables, particularly in long-span members, helps to reduce the shear forces developed at the support sections.

A prestress concrete flexural member is stiffer under working loads than a reinforced concrete member of the same depth. However, after the onset of cracking, the flexural behavior of a prestressed member is similar to that of a reinforced concrete member. The use of the high strength concrete and steel in prestress members results in lighter and slender members than is possible with reinforced concrete. The two structural features of prestressed concrete namely high strength concrete and freedom from cracks, contributes to the improved durability of the structures under aggressive environmental conditions. Prestressing of concrete improves the durability of material for energy absorption under impact loads. The ability to resist repeated working loads has been proved to be as good in prestressed as in reinforce concrete.

The economy of the prestressed concrete is well established for long span structures. According of Dean 6 standardized precast bridge between 10 to $30 \mathrm{~m}$ long precast prestressed piles have proved to be more economical than steel and reinforced concrete in the United States. According to Abeles 7, pre cast prestress concrete is economical for floors, roofs and bridges of spans up to $30 \mathrm{~m}$, and for cast in situ work, up to $100 \mathrm{~m}$. In the long-span range, prestressed concrete is generally more economical than reinforced concrete and steel.

\section{Finite Element Analysis:-}

Finite element analysis is an effective method of determining the static performance of structures for three reasons which are saving in design time, cost effective in construction and increase the safety of the structure. Previously, it is necessary to used advanced mathematical methods in analysis large structures, such as bridges, tall buildings and other. More accuracy generally required more elaborate techniques and therefore a large friction of the designer's time could be devoted to mathematical analysis. Finite element methods free designer's from the need to concentrate on mathematical calculation and allow them to spend more time on accurate representation of the intended structure and review of the calculated performance (Smith, 1988) [11].

Furthermore, by using the programs with interactive graphical facilities, it is possible to generate finite element models of complex structures with considerable ease and to obtain the results in a convenient, readily assimilated form. This may save valuable design time. More accurate analysis of structure is possible by the finite element method leading to economics in materials and construction also in enhancing the overall safety (De Salvo and Swanson, 1985) [12].

However, in order to use computer time and design time effectively, it is important to plan the analysis strategy carefully. Before a series of dynamic tests carry out in the field, a complete three-dimensional finite element models are developed for each bridges, prior to its testing. The results from these dynamic analyses are used to select instrument positions on the bridge and predict static displacement. Then, they are calibrated using the experimental frequencies and mode shapes. The frequencies and mode shapes mainly are used to provide a basis for the study of the influence of certain parameters on the dynamic response of the structure, the influence of secondary structural elements, the cracking of the deck slabs, the effects of long-term concrete creep and shrinkage and so on (Paultre and Proulx, 1995) [13]. Besides, more sophisticated methods based on finite element or finite strip representation have been used by some researchers to study the dynamic behavior of bridges, Fam (1973) and Tabba (1972) studied the behavior of curved box section bridges using the finite element method for applied static and dynamic loads. A three-dimensional finite element analysis program was developed for curved cellular structures. Solutions of several 
problems involving static and dynamic responses were presented using the proposed and other sophisticated methods of analysis. An experimental study conducted on two curved box girder Plexiglas models confirmed the reliability of the proposed methods of analysis.
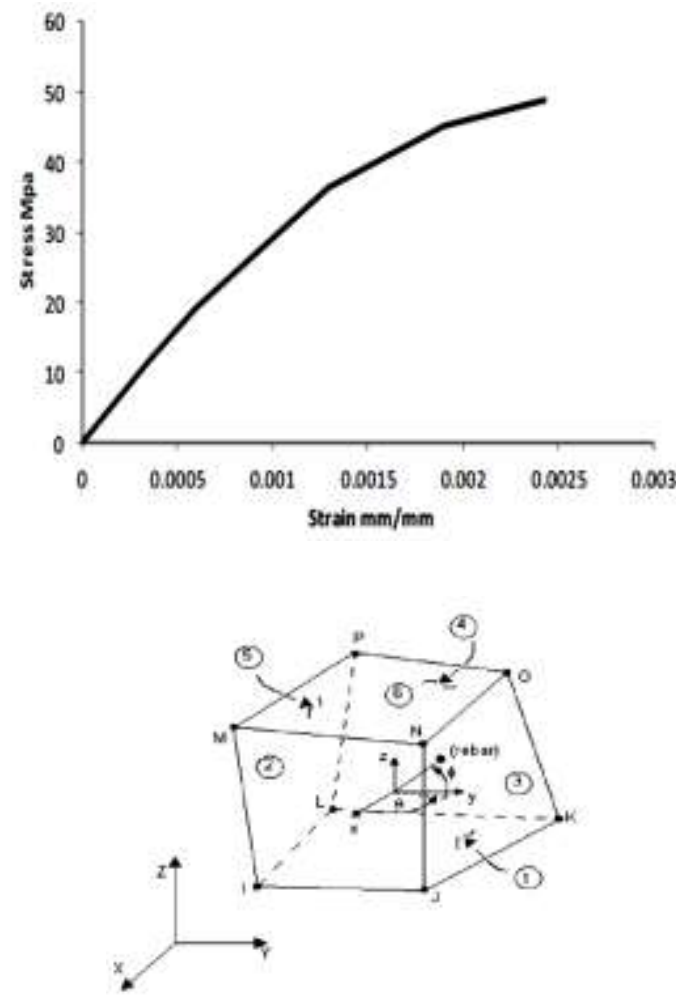

Figure-1:- Solid65 element.

\section{Modeling Of Rc Beam:-}

The solid65 element models the nonlinear response of reinforced concrete. The behavior of the concrete material is based on a constitutive model for the tri-axial behavior of concrete after Williams and Warnke [14]. Solid 65 is capable of plastic deformation, cracking in three orthogonal directions at each integration point. The cracking is modelled through an adjustment of the material properties that is done by changing the element stiffness matrices. If the concrete at an integration point fails in uniaxial, biaxial, or tri-axial compression, the concrete is assumed crushed at that point. Crushing is defined as the complete deterioration of the structural integrity of the concrete. ANSYS allows entering three reinforcement bars materials in the concrete, each rebar material or responds to the $\mathrm{x}$, $\mathrm{y}$, and $\mathrm{z}$ directions of the smeared element. A schematic of the element is shown in Figure-1.

\section{Material Properties:-}

Table-1 lists concrete properties within Solid65 element prior to initial yield surface, beyond that concrete parameters are shown in Table-2. The solid65 element is capable of cracking in tension and crushing in compression. The multi linear isotropic concrete model uses the von Mises failure criterion along with Willam and Warnke model to define the failure of concrete.

Table-1:- Concrete properties prior to initial yield surface.

\begin{tabular}{|c|c|c|c|}
\hline Material & Material Model & Modulus of Elasticity & Poisson's Ratio \\
\hline concrete & Linear Elasticity & 25743 & 0.3 \\
\hline
\end{tabular}

Table-2:- Concrete parameters beyond initial yield surface.

\begin{tabular}{|l|l|}
\hline Open shear transfer coefficient & $\beta \mathrm{t} 0.3$ \\
\hline Closed shear transfer coefficient & $\beta \mathrm{c} 0.9$ \\
\hline Uniaxial cracking stress & $3.78 \mathrm{MPa}$ \\
\hline
\end{tabular}


\begin{tabular}{|l|l} 
Uniaxial crushing stress $\sigma_{c}^{\prime}$ & $50 \mathrm{MPa}$
\end{tabular}

Figure-2:- Concrete stress strain curve for unidirectional monotonic compressive loading.

The compressive uniaxial stress-strain relationship for the concrete model in Figure-2 was obtained using the following equations to compute the multilinear isotropic stress-strain curve for the concrete.

Where

$$
\sigma=\frac{E_{c} \varepsilon}{1+\left\{\frac{\varepsilon}{\varepsilon_{0}}\right\}^{2}} \quad E_{c}=\frac{\sigma}{\varepsilon} \quad \varepsilon_{0}=\frac{2 \sigma_{c}^{\prime}}{E_{c}}
$$

$\sigma=$ stress at any strain

$\varepsilon=$ strain at stress $\sigma$

$\varepsilon_{0}=$ strain at ultimate compressive strength

$E_{c}=$ concrete modulus of Elasticity

Cracking and crushing are determined by a failure surface. Once the failure surface is surpassed, concrete cracks, if any, principal stress is tensile, while the crushing occurs if all principal stresses are compressive. The failure surface for compressive stresses is based on Willam-Warnke failure criterion which depends on five material parameters. Tensile stress consists of a maximum tensile stress criterion: a tension cutoff. Unless plastic deformation is taken into account, the material behavior is linear elastic until failure. When the failure surface is reached, stresses in that direction have a sudden drop to zero, there is no strain softening neither in compression nor in tension. Two shear transfer coefficients are presented in Table-2, one for open cracks and the other for closed ones, and are used to consider the retention of shear stiffness in cracked concrete. As shown in Figure-3, Material Model for steel reinforcement is linear elastic prior to initial yield surface, beyond the initial yield surface it is perfectly plastic, in tension and compression loading.

Table-3:- Properties for the steel reinforcement.

\begin{tabular}{|l|l|}
\hline Material model prior to initial yield surface & Linear elastic \\
\hline Elastic modulus Es & $200 \mathrm{GPa}$ \\
\hline Poisson's ratio & $v=0.3$ \\
\hline Yield stress $\sigma_{y}$ & $412 \mathrm{MPa}$ \\
\hline
\end{tabular}

Material model beyond initial yield surface and up to failure perfect plastic Table-3 lists the properties of the 4 \#12 mm bars steel reinforcement.

\section{Loads And Boundary Conditions:-}

The model is considered symmetric about a vertical section at mid span, a distance $2.5 \mathrm{~m}$ from the left support. Thus the computer model section width is $0.15 \mathrm{~m}$, and section depth is $0.15 \mathrm{~m}$ as shown in Figure-4. Nodes defining a vertical plane through the beam cross-section at mid span that is a distance of $0.9 \mathrm{~m}$ from left support, define a plane of symmetry, nodes on this plane have a degree of freedom constraint $u_{x}=0$. Nodes defining a vertical plane at half the cross section width, define another plane of symmetry, nodes at this plane have a degree of freedom constraint $\mathrm{u}_{\mathrm{z}}$ $=0$. The boundary conditions for both planes of symmetry, supports and loadings are shown in Figure-4.

\section{Numerical Example:-}

The proposed solution technique has validated through simple comparison of the calculated maximum deflection at the mid-span with the experimental maximum deflection measured at the same location. The comparison is presented in Table 4.

Table 4:- Maximum deflection calculated versus maximum deflection measured.

\begin{tabular}{|c|c|c|c|c|c|}
\hline Groups & & Beams & $\begin{array}{c}\text { Max Load } \\
(\mathrm{Kn})\end{array}$ & $\begin{array}{c}\text { Measured } \\
\text { Deflection (mm) }\end{array}$ & $\begin{array}{c}\text { Calculated } \\
\text { Deflection (mm) }\end{array}$ \\
\hline \multirow{2}{*}{ Group $(1)$} & 1 & $B 1$ & 246 & 57.6 & 59.01 \\
\cline { 2 - 6 } & 2 & $B 1-1(s)$ & 216 & 48 & 46.42 \\
\cline { 2 - 6 } & 3 & $B 1-1(R)$ & 212 & 68 & 66.62 \\
\hline
\end{tabular}




\begin{tabular}{|l|c|c|c|c|c|}
\hline \multirow{5}{*}{ Group(2) } & 4 & $B 1-2(s)$ & 224 & 41 & 42.48 \\
\cline { 2 - 6 } & 5 & $B 1-2(R)$ & 223 & 55 & 54.78 \\
\hline & 6 & $B 2$ & 158 & 67 & 73.47 \\
\cline { 2 - 6 } & 7 & $B 2-1(S)$ & 156 & 55 & 57.65 \\
\cline { 2 - 6 } & 8 & $B 2-1(R)$ & 146 & 60 & 54.53 \\
\cline { 2 - 6 } & 9 & $B 2-2(s)$ & 150 & 55 & 50.34 \\
\cline { 2 - 6 } & 10 & $B 2-2(R)$ & 146 & 55 & 54.91 \\
\hline
\end{tabular}

The adopted reinforced presterssed concrete beams with opening studded in this work are identical to that studded by Authors. Beams are simply supported and loaded with two symmetrically placed concentrated transverse loads. This study considers two categories of beams (B1 and B2) based on the shear span to the total depth ratio (a/d), B1 $(\mathrm{a} / \mathrm{d}=2.5)$ and B2 $(\mathrm{a} / \mathrm{d}=4.0)$. Based on the early study reported by Somes and Corley (1974), each category includes two shapes of small opening holes, the first is square open hole (S) with side length $0.1 \mathrm{~m}$ and the second is rectangle open hole $(\mathrm{R})$ with length $0.2 \mathrm{~m}$ and width $0.1 \mathrm{~m}$. The beam cross-section main dimensions are configured in width $=0.15 \mathrm{~m}$, total depth $=0.35 \mathrm{~m}$, and effective span length $=5.0 \mathrm{~m}$ as presented in figure (3). The studied cases are summarized in figure 4.

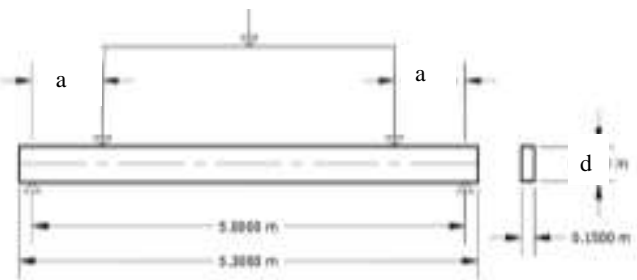

Figure-3:- Beam main dimensions

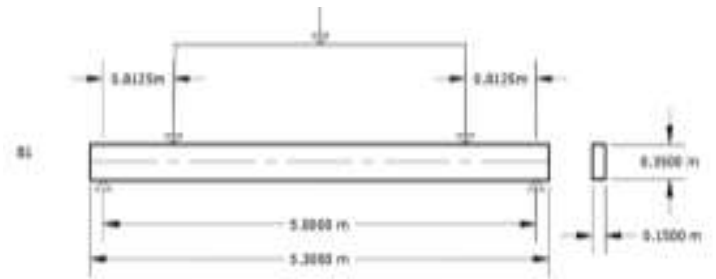

(a) Solid Beam a/d $=2.5$

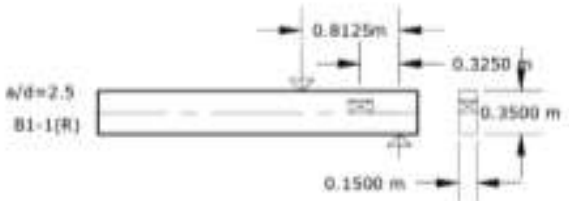

(b) B1- $1(\mathrm{R})$

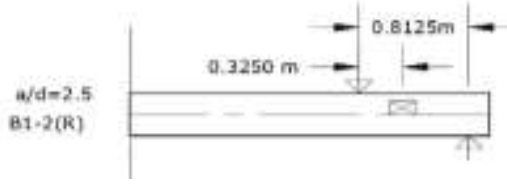

(d) $\mathrm{B} 1-2(\mathrm{R})$

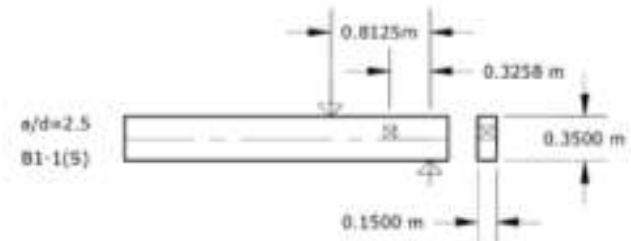

(c) $\mathrm{B} 1-1(\mathrm{~S})$

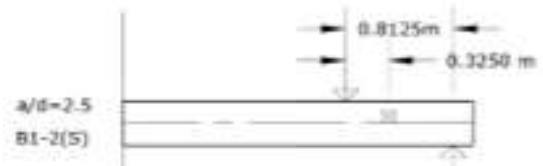

(e) $\mathrm{B} 1-2(\mathrm{~S})$

Figur (4) Beam with opening at shear span to total depth ratio $\mathrm{a} / \mathrm{d}=2.5$

Four cases of B1 shown in figure 4, has been studied. Two cases are with square opening and two with rectangular opening. In the first two one square opening is located away from the support by distance $0.325 \mathrm{~m}(\mathrm{~B} 1-1 \mathrm{~S})$ and the second is located away from the load point position by the same distance 0.325 (B1-2S). The other two are with rectangular opening located with the same distance labaled with (B1-1R) and (B1-2R). Figure 5, prsents the shear stress distribution on the beam material based on the maximum shear theory for B1 categury. The first case B1-1S the maximum shrear stress is $16.9 \mathrm{MPa}$ while in $\mathrm{B} 1-2 \mathrm{~S}$ case the maximum shear stress is $15.487 \mathrm{MPa}$. This means the location of the opening plays a strong role in the shear stress value and distribution. The same effect is depected in the case of B1-1R the maximum shear stress is $15.8 \mathrm{MPa}$ while for $\mathrm{B} 1-2 \mathrm{R}$ the maximum shear is $15.0 \mathrm{MPa}$. 
The maximum equivalent stress calculated based on the maximum distorsion energy theory shows the same behavior as presented in figure 6. It is noteced that maximum equivalent stress for B1-1S is equale to $29.71 \mathrm{MPa}$, while for B1-2S is $27.10 \mathrm{MPa}$; and for B1-1R the maximum equevalet stress is $27.68 \mathrm{MPa}$ but for B1-2R is 26.29 $\mathrm{MPa}$. It is also detected that the stress concentration around the opening has incresed as the open close to the point of force application. The iso-stress contors illusrates that the most cretical case is B1-2R and the failure shall start at the upper corner close to the force which comply the experimental results shown in figure 7.

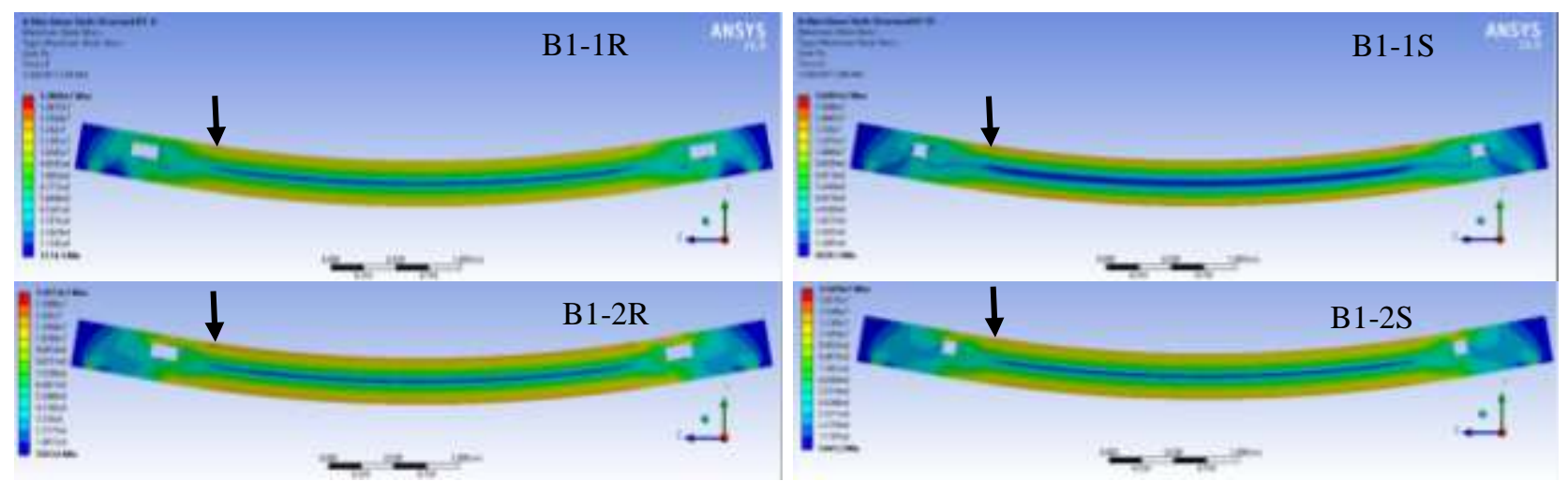

Figure 5:- Shear Stress Distribution Contours Based On Maximum Shear Theory

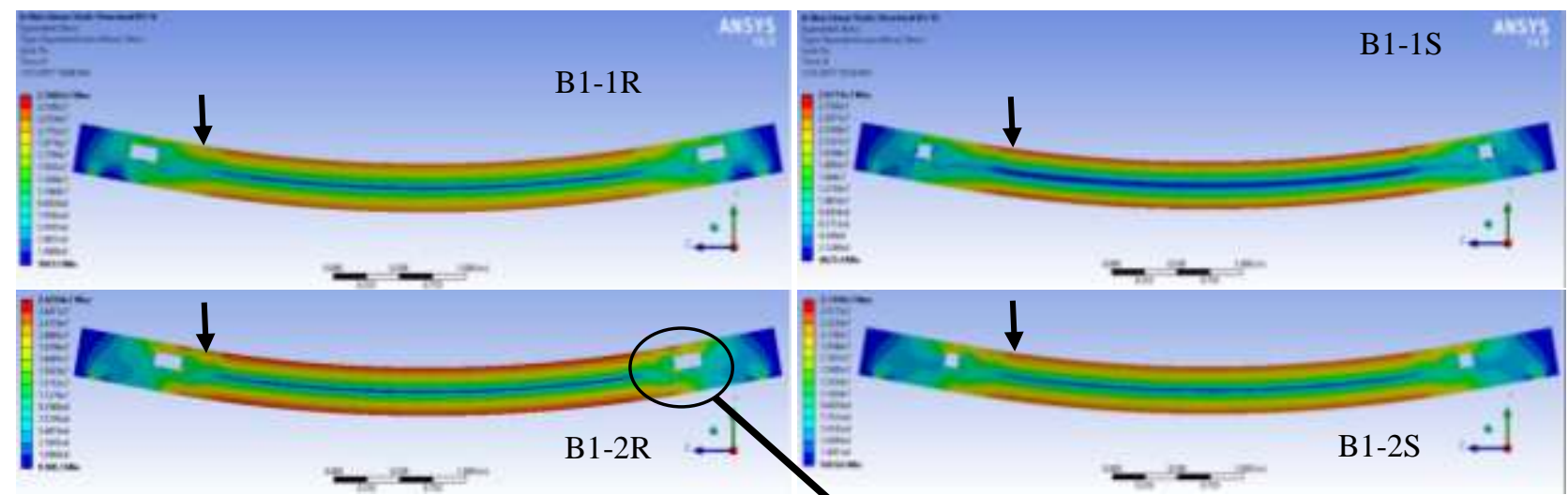

Figure 6:- Equivalent Stress Distribution Compurs Based On Maximum Distortion

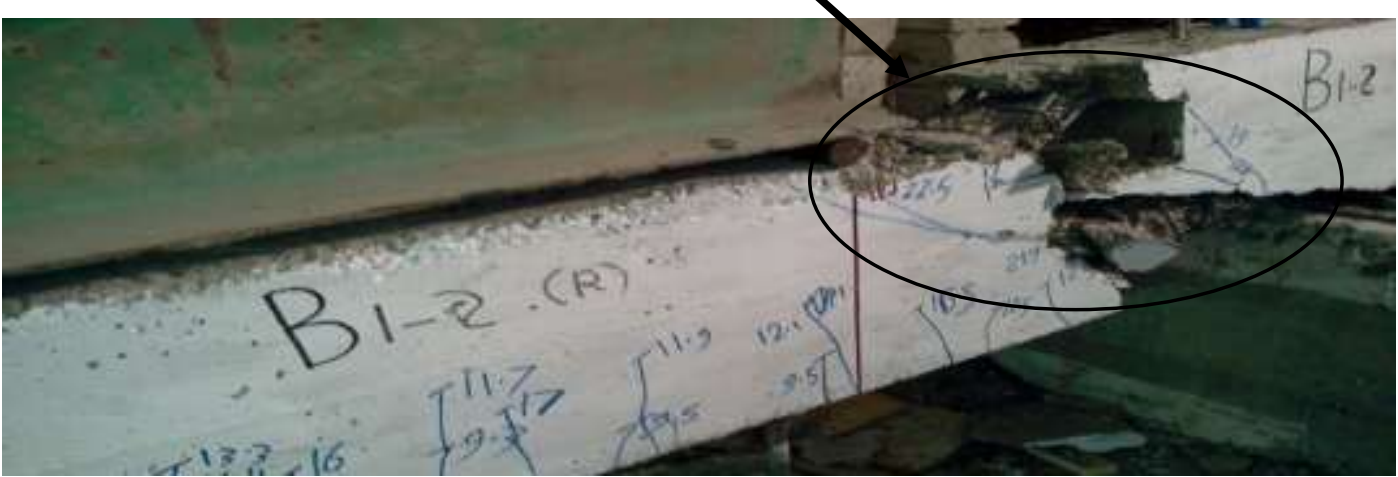

Figure 7:-

The second set includes five beams identical in overall dimensions, one solid and two with square opening side dimension $0.1 \mathrm{~m}$ and two rectangular opening with $0.2 \mathrm{~m}$ length and $0.1 \mathrm{~m}$ width, loaded by transverse line load away from both side supports by $1.3 \mathrm{~m}$. Detail discerption are presented in figure 8 . 


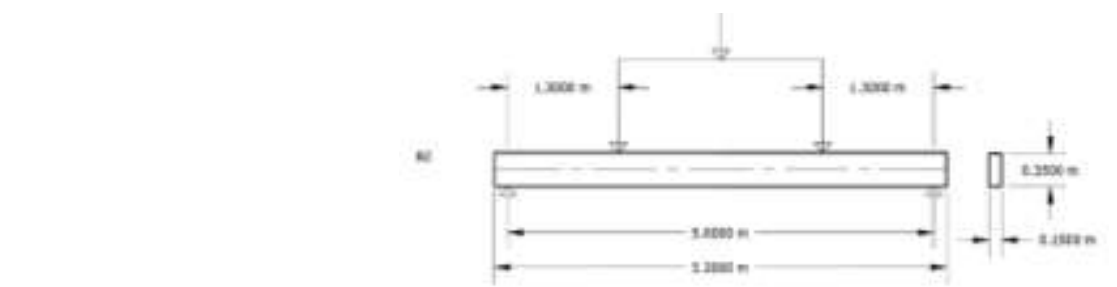

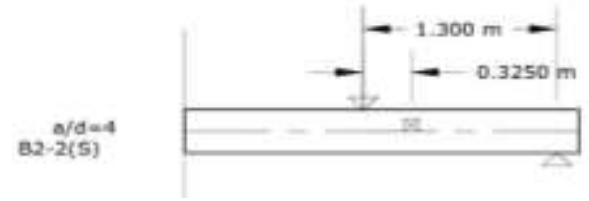

(b)

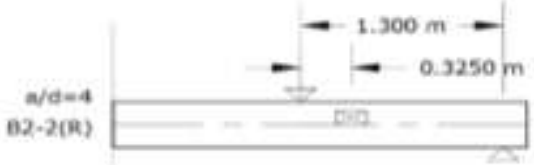

(d)

(a) Solid Beam a/d $=4.0$

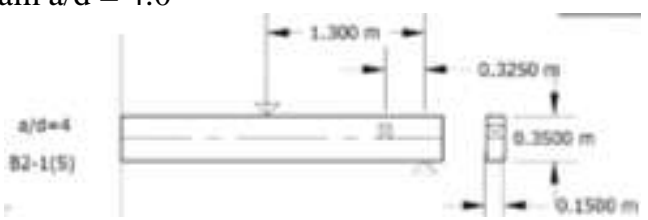

(c)

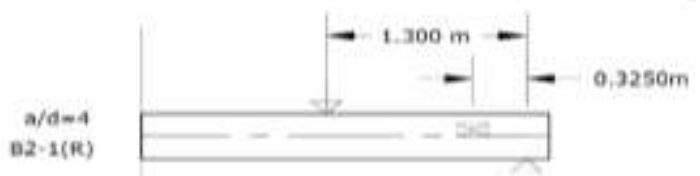

(e)

Figur (8) Beam with opening at shear span to total depth ratio $\mathrm{a} / \mathrm{d}=4.0$

The shear stress distribution in beams are presented in figures 9. It shows that in case B2-1S the maximum shear stress $14.95 \mathrm{MPa}$ while in case B2-2S the maximum shear stress is $15.97 \mathrm{MPa}$. In case B2-1R $14.52 \mathrm{MPa}$ and in case B2-2R 16.45 MPa. It is depicted that the shear stress behavior of B2 cases are opposite to the behavior of B1 cases.

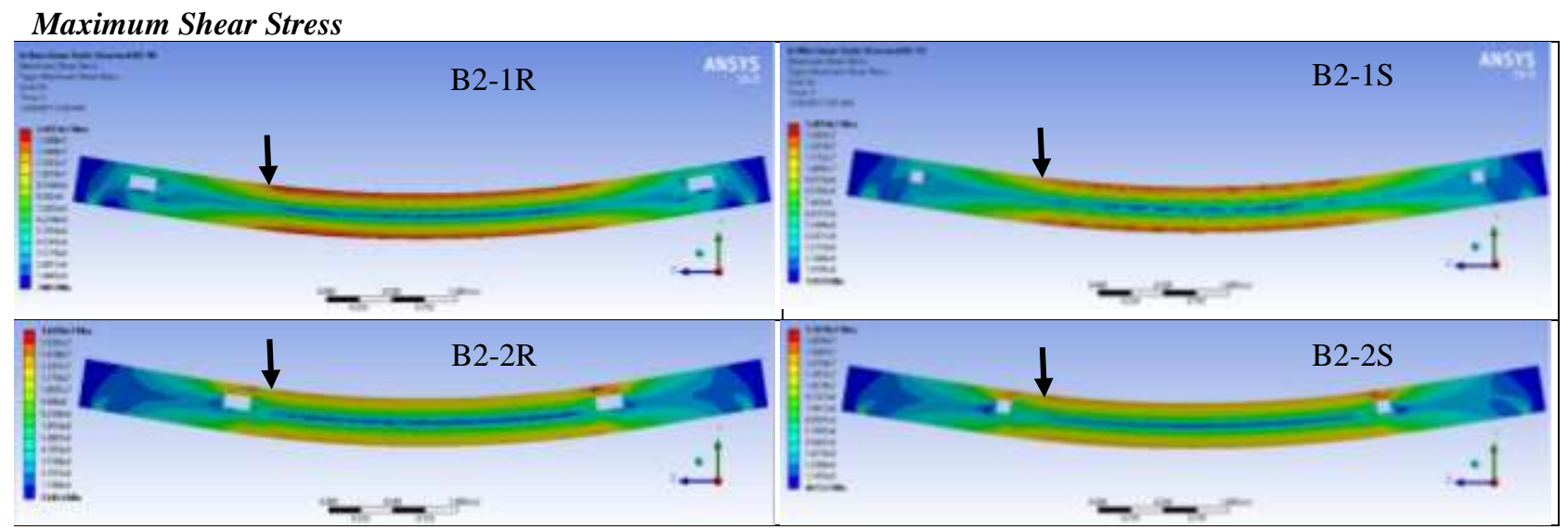

Figure 9. The shear stress distribution on

\section{Equivalent Stress:-}

The equivalent stress distribution in beams are presented in figures 10. It shows that in case B2-1S the maximum equivalent stress $28.41 \mathrm{MPa}$ while in case B2-2S the maximum shear stress is $29.54 \mathrm{MPa}$. In case B2-1R 28.34 MPa and in case B2-2R 32.22 MPa. It is depicted that the shear stress behavior of B2 cases are opposite to the behavior of B1 cases.

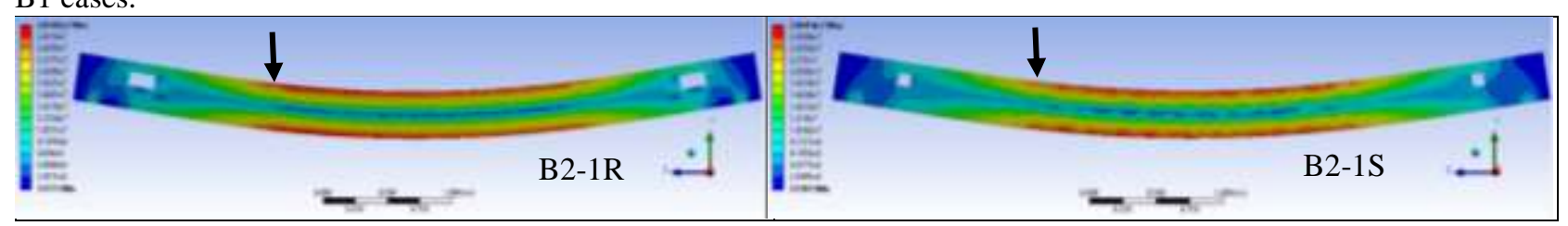




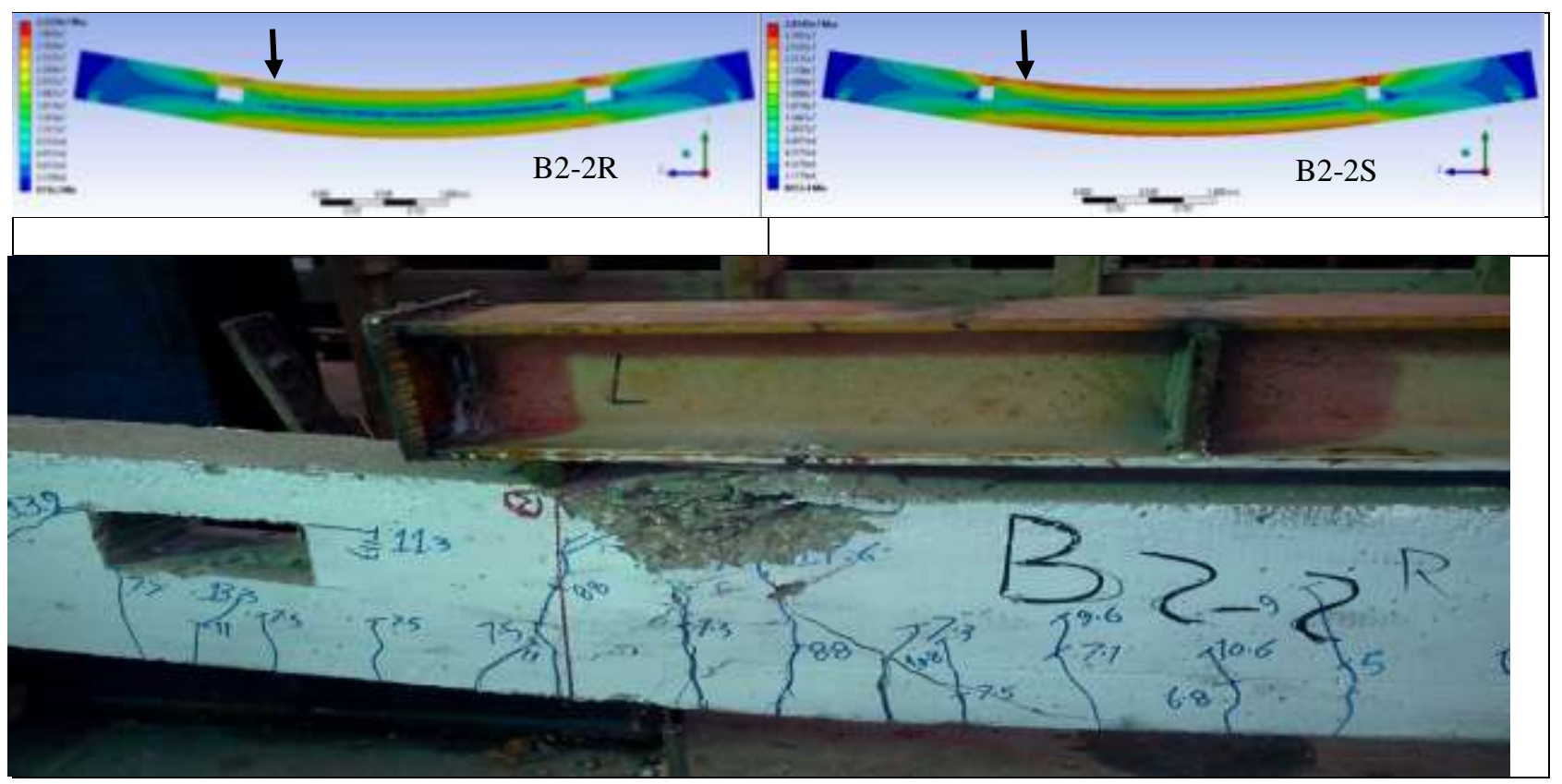

Figure 9

\section{Conclusion:-}

1. Presence of openings leads to decrease the strength compared with the beams without openings.

2. The strength decrease with increase the size of openings.

3. The strength increase with increase span-depth ratio $(\mathrm{a} / \mathrm{d})$.

4. For the location of openings it was noted that:-

In case of group (1) $\{\mathrm{a} / \mathrm{d}=2.5\}$, with the location of openings near the support (X1) that leads to decrease the strength, while with the location of openings near the applied load (X2), that leads to increase the strength.

In case of group (2) $\{\mathrm{a} / \mathrm{d}=4\}$, with the location of openings near the support (X1) that leads to increase the strength, while with the location of openings near the applied load (X2) that leads to decrease the strength.

\section{References:-}

1. Hanson, J.M., Square openings in webs of continuous joists, Portland Cement Association, 1969,pp: 1-14.

2. Somes, N.F. and W.G. Corley, Circular openings webs of continuous beams, American Concrete Institute, Detroit, MI, 1974, pp: 359-398.

3. Salam, S.A., Beams with openings under different stress conditions, Conference on Our World in Concrete and Structures, Singapore, 25-26 Ague, 1977, pp.: 259-267.

4. Siao, W. B., \& Yap, S. F. (1990). Ultimate behaviour of unstrengthen large openings made in existing concrete beams. Journal of the institution of Engineers, Singapore, 30(3), 51-57.

5. M.A. Mansur, "Design of Reinforced Concrete Beams With Web Opening", Proceedings of the 6th Asia-Pacific Structural Engineering and Construction Conference (APSEC 2006), 5 - 6 September 2006, Kuala Lumpur, Malaysia.

6. Mansur, M.A. "Effect of openings on the behavior and strength of $\mathrm{R} / \mathrm{C}$ beams in shear. Cement and Concrete Composites", Elsevier Science Ltd., Vol. 20, No. 6, pp. 477-486, (1998).

7. Abdalla, H. A., Torkey, A. M., Haggag, H. A., \& Abu-Amira, A. F. (2003). Design against cracking at openings in reinforced concrete beams strengthened with composite sheets. Composite Structures, 60(2), 197-204.

8. T.H. Kim1, J.H. Cheon2 and H.M. Shin "Evaluation of behavior and strength of prestressed concrete deep beams using nonlinear analysis" Computers and Concrete, Vol. 9, No. 1 (2012) 63-79.

9. Abdul Ridah Saleh Al-Fatlawi, Hayder Ali Abed, "CFRP Strengthening Of Concrete Slabs With And Without Openings”, International Journal of Scientific \& Technology Research, Vol. 4, Issue 8, August 2015.. 
10. M.A. Mansur, "Design of Reinforced Concrete Beams With Web Opening", Proceedings of the 6th Asia-Pacific Structural Engineering and Construction Conference (APSEC 2006), 5 - 6 September 2006, Kuala Lumpur, Malaysia

11. I. M. SMith and D. V. GRIFfiths, "Programming the finite Element Method 2ND EDN", Wiley, CHICHESTER, 1988.

12. De Salvo, G.J., and Swanson, J.A. (1985). ANSYS, Engineering Analysis System (Vols. I and II, rev. 4.2), Houston, PA.

13. P. Paultre, and J. Proulx and M. Talbot, "Dynamic Testing procedures of concrete" Proceding of the International Bridges Using Traffic Loads, Journal of Structural ngineering, Vol. 121, No. 2, pp. 362-376, 1995.

14. William, K.J. and Warnke, E.D. "Constitutive Model for the Triaxial Behaviour of Concrete", Proceedings of the International Association for Bridge and Structural Engineering, 1975, 19, p.174, ISMES, Bergamo, Italy. 